\title{
O massacre do paralelo 11 e os direitos fundamentais a partir do direito de memória Indígena e a decolonização do direito brasileiro
}

\author{
Alianna Cardoso Vançan ${ }^{1}$ \\ Milena Valle Rodrigues ${ }^{2}$
}

\begin{abstract}
Resumo
O presente artigo tem como objetivo demonstrar o impacto da repressão do Regime Militar à população indígena, a partir do nominado Massacre do Paralelo 11 - ocorrido no norte do Estado de Mato Grosso, contra o povo CintaLarga, como parâmetro para dialogar acerca da efetividade dos direitos fundamentais constitucionalmente consagrados, mediante o princípio da dignidade da pessoa humana fundamentado no direito à memória indígena e na decolonização do pensamento jurídico. Adotamos no presente estudo o método materialista histórico-dialético de Evgeni Pachukanis para dialogar a partir da experiência do real, a relação entre a norma jurídica e a necessidade de rever a reificação dos povos indígenas no Estado Democrático de Direito. Assim, investigamos os trabalhos da Comissão Nacional da Verdade e posteriormente conceituamos memória e direitos fundamentais, para ao final, analisarmos como a memória em suas constituições identitárias e em suas lutas por reconhecimento e a decolonização do pensamento jurídico nacional são necessárias para o exercício de direitos fundamentais pelos povos tradicionais.
\end{abstract}

Palavras-chave: Indígenas; Direitos fundamentais; Decolonização; Memória; Dignidade da pessoa humana.

\section{Introdução}

O objeto deste artigo é a análise crítica à efetividade dos direitos fundamentais dos povos indígenas, considerando o regime militar brasileiro. Para isso, foi necessária uma abordagem interdisciplinar, com o apoio de revisões bibliográficas na área da história, da antropologia, da sociologia e da filosofia, levando em conta que o direito nem sempre consegue responder a questões relativas a processos sociais e políticos apresentados na historiografia brasileira. A hipótese inicial é de que tanto a historiografia quanto o pensamento jurídico nacional destinaram um local secundário aos povos que tradicionalmente ocupam as terras brasileiras.

O objetivo geral é instituir um diálogo acerca dos direitos fundamentais dos povos indígenas a partir do direito de memória e da decolonização do pensamento jurídico nacional, explorando a inteligência que esses conceitos podem proporcionar à nossa sociedade. Optou-se pelo método dedutivo, uma vez que se partiu de conceitos universais como poder, memória e

\footnotetext{
${ }^{1}$ Mestra em Filosofia pela Universidade Federal de Mato Grosso; Mestra em Direito pela Universidade Federal de Mato Grosso. Doutoranda em Filosofia pela Universidade Federal de Pelotas; E-mail: cardosovancan@gmail.com.
}

${ }^{2}$ Mestranda em Direito pela Universidade do Estado do Rio de Janeiro; E-mail: milenavalle@gmail.com 
justiça até chegarmos a um objeto mais específico que é a possibilidade de um olhar decolonial para os direitos fundamentais.

Adotou-se para o presente estudo o método de abordagem materialista históricodialético de Evgeni Pachukanis (1989) e a metodologia de pesquisa bibliográfica, como forma de diálogo com o real, a partir da contraposição de ideias e perspectivas, em especial essas que se contrapõem em face do debate da reificação dos corpos estigmatizados, vulnerabilizados e invisibilizados pela luta por poder que operou no Brasil desde sua colonização e coisificou os povos indígenas. A partir do enfoque em pesquisa bibliográfica e documental, bem como análise histórico-crítica, a dialética torna exequível a revolução do status quo por possibilitar a compreensão de que o mundo é sempre resultado da práxis humana (ZAGO, 2013, p. 109)

O trabalho está estruturado em três tópicos. Em primeiro lugar analisamos os trabalhos da Comissão Nacional da Verdade, o resgate do Relatório Figueiredo e trazemos uma das mais graves violações de direitos dos povos tradicionais dos povos indígenas, que ficou conhecido como o Massacre do Paralelo 11. Posteriormente, nos dedicamos aos conceitos de memória e direitos fundamentais. Por fim, analisamos como as lembranças dos ataques ditatoriais aos povos tradicionais brasileiros, em suas constituições identitárias e em suas lutas por reconhecimento e a decolonização do pensamento jurídico nacional são necessárias para o exercício de direitos fundamentais pelos povos tradicionais.

\section{Os trabalhos da Comissão Nacional da Verdade e o regaste do Relatório Figueiredo}

Sabe-se pouco acerca dos crimes cometidos pela repressão militar no Brasil contra os povos indígenas. Este artigo tem como objetivo resgatar a história do Massacre do Paralelo 11, um genocídio que ocorreu contra a etnia indígena Cinta-Larga no norte do Estado de Mato Grosso, em meados dos anos 60, do século XX. O episódio em si registra poucas pesquisas acadêmicas, embora tenha sido objeto do filme "Avaeté - a semente da vingança", de autoria do cineasta Zelito Viana, em 1985.

As narrativas a respeito do período militar nunca tiveram o indígena como foco, o que poderia dar a impressão de que a política repressiva passou longe das aldeias indígenas, tanto que não fazia parte da proposta inicial da Comissão Nacional da Verdade, instituída para investigar violações a direitos humanos no período militar (VALENTE, 2017, p. 55). Um email enviado por um índio Marubo, ao grupo Tortura Nunca Mais de São Paulo, questionou: “por que vocês só veem mortos e desaparecidos e não os índios?”. A partir dessa correspondência se deu a articulação para que o tema fosse incluído na pauta da Comissão Nacional da Verdade (LIMA, 2017, p. 349). 
A inclusão dos povos indígenas como objeto de estudo na Comissão Nacional da Verdade revelou que os atingidos pela repressão não se limitavam apenas ao grupo de pessoas que se opunham ao regime. Durante os trabalhos da Comissão, foram recuperados documentos importantes para a compreensão da extensão da violência estatal contra esses grupos. Em dezembro de 2012, o ativista Marcelo Zelic recuperou 29 dos 30 tomos originais do documento conhecido como Relatório Figueiredo - que era dado como desaparecido num incêndio que ocorreu no Ministério da Agricultura no ano de 1967 (LIMA, 2017, p. 353).

O relatório é produto de uma investigação feita em plena ditadura, conduzida pelo Procurador Jader de Figueiredo Correia durante os anos de 1967 e 1968. A documentação possui 7 mil páginas, permanece sob a tutela do Museu do Índio/Funai no Rio de Janeiro e está disponível $\underline{\text { online }}^{3}$. O documento descreve torturas, assassinatos, exploração sexual e vários tipos de violência praticados por latifundiários brasileiros e por funcionários do Serviço de Proteção ao Índio (SPI), ao longo dos anos de 1940, 1950 e 1960.

Dentre os vários episódios relatados pelo Relatório Figueiredo, destaca-se o que ficou conhecido como Massacre do Paralelo 11 - objeto deste artigo. Trata-se de uma chacina que dizimou por volta de 3.500 indígenas da etnia Cinta Larga, que ocorreu na região norte do Estado de Mato Grosso, à beira do Rio Aripuanã, cujas terras eram reservas de diamantes, de grande repercussão internacional à época dos fatos, e que foi comprovado de maneira ampla em processo judicial aberto no Estado de Mato Grosso (VALENTE, 2017, p. 210).

Eram definidos como "Cinta-Larga ou "Cinturão Largo" os diversos grupos indígenas que habitavam a região próxima à fronteira entre Rondônia e Mato Grosso, uma vez que todos usavam o mesmo tipo de cinto (confeccionado com uma casca de árvore) e construíam grandes malocas oblongas. Com uma população bem mais numerosa há décadas, segundo informantes e fontes escritas, cada agrupamento ou subgrupo era formado por aldeias mais ou menos próximas.

João Dal Poz Neto (1991, p. 55) traz o contexto histórico da ocorrência do genocídio contra os Cintas-Largas:

Desde meados da década de 50 o território indígena vinha sofrendo a pressão crescente de firmas seringalistas e empresas de mineração, situação que se agravou com a inauguração da estrada Cuiabá-Porto Velho (BR 364) em 1960. Hostis aos invasores, os Cinta Larga representavam empecilho à expansão destes empreendimentos, principalmente pelos afluentes dos rios Juruena e Aripuanã. E assim, ganharam proporções alarmantes as operações destinadas a "limpar a área", organizadas pela firma Arruda \& Junqueira e outras, que vinham explorando seringais e pesquisando ouro e diamante na região.

\footnotetext{
${ }^{3}$ Relatório Figueiredo. Museu Nacional do Índio. Rio de Janeiro, 1967. Disponível em: <http://www.docvirt.com/docreader.net/docmulti.aspx?bib=museudoindio\&pagfis=> Acesso em: 18.01.2021
} 
O crime foi confessado por um dos participantes que não recebendo o pagamento prometido, compareceu à sede do Serviço de Proteção ao Índio, em Cuiabá, e denunciou o caso, apontando os mandantes da ação. A expedição organizada para retirar os indígenas da área partiu em julho de 1963, da sede da empresa mineradora Arruda \& Junqueira. Os pistoleiros andaram por meses na mata, seguindo as picadas dos Cintas-Largas e sendo abastecidos por munições e alimentos que eram lançados por um avião. Conforme avançavam pela mata, foram mortos muitos indígenas, homens, mulheres e crianças, com requintes de crueldade (POZ NETO, 1991, p. 56). Alguns desses incidentes foram registrados em fotografias. Como a da mulher indígena que teve seu corpo pendurado pelos tornozelos, na imagem abaixo:

Figura 1: Mulher indígena pendurada pelos tornozelos. Foto atribuída ao Massacre do Paralelo $11^{4}$.

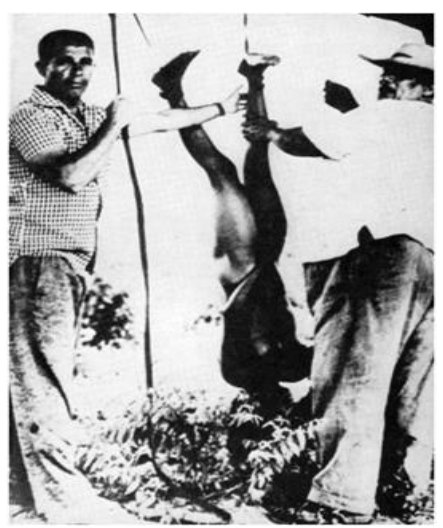

Fonte: Jornal O Globo. Missionário Jesuíta reforça acusação de que genocídio dos índios continua. 25 de janeiro de 1966, p. 15.

O que aconteceu após o registro dessa imagem foi a chocante e feroz divisão do corpo da indígena ao meio, por golpes de facão. O Massacre do Paralelo 11 foi tido como uma das denúncias mais graves do Relatório Figueiredo. Darcy Ribeiro, na obra Os índios e a civilização, resgatou alguns processos de guerras e invasões a terras indígenas e traz descrições que foram publicadas na imprensa acerca desses eventos. Acerca do Massacre do Paralelo 11, retoma uma reportagem de Ronald de Carvalho, publicada em 1968 na Revista Fatos \& Fotos (1990, p. 209 - 210) descrevendo o episódio:

[...] ocorre, então, o seguinte episódio: "Após terem metralhado um grupo de índios acampados junto a um rio, os homens da expedição ouviram um choro de criança, abafado pela mão da mãe. Para os que deviam regressar na manhã seguinte com a missão cumprida, aquele pequeno ruído mostrava que o serviço não fora perfeito.

\footnotetext{
${ }^{4}$ A imagem acima, da mulher indígena pendurada pelos tornozelos é apontada como registro do Massacre do Paralelo 11 tanto por entidades de defesa dos povos tradicionais: https://www.survivalbrasil.org/ultimasnoticias/9197, como em trabalhos acadêmicos (BARBOSA, 2016, p. 257).
} 


\begin{abstract}
Rapidamente eles acendem as lanternas e saem vasculhando o mato. Sob dois corpos crivados de balas estavam escondidas mãe e filha. Os homens que as encontraram fizeram uma festa. Dois tentavam violentar a mulher e um beliscava a garotinha que chorava, vendo a aflição da mãe. Em volta fechando o círculo, o grupo se divertia. Nas mãos dos dois nordestinos fortes a mulher índia se debatia. Nesse instante, aproveitando um descuido, a criança libertou-se, correu em socorro da mãe e, com raiva, mordeu a perna de um dos homens. A mulher em pânico tentava cuidar da menina e, ao mesmo tempo, livrar-se dos homens que a violentavam. O homem com a perna mordida foi substituído por outro, afastou-se da índia e com ódio começou a estrangular a criança. Alguém, querendo terminar com o espetáculo paralelo que atrapalhava o primeiro, tomou a menina das mãos de seu estrangulador e lhe deu um tiro de pistola 45 na cabeça. A testa da garotinha explodiu e o sangue salpicou a roupa dos que estavam em volta. Vendo a filha morta, a mulher não resistiu e desmaiou. Indefesa nas mãos dos chacinadores, a índia foi violentada por todos e depois retalhada a facão". (Ibidem)
\end{abstract}

Um dos incidentes mais sangrentos ocorridos na região da Amazônia brasileira, que foi objeto de apuração judicial, mas nenhum dos envolvidos foi punido (VALENTE, 2017, p. 83).

O relatório final da Comissão Nacional da Verdade avançou ao reconhecer as violações dos direitos dos povos tradicionais, no entanto, uma medida de fácil execução indicada no texto da $\mathrm{CNV}$, como o pedido público de desculpas da União pelos erros cometidos, recomendação datada de 2014, ainda é ignorada pelo Estado brasileiro (VALENTE, 2017, p. 07) A pesquisa aponta que esses pedidos de perdão aos povos tradicionais ocorrem como consequência de casos que se encontram judicializados. ${ }^{5}$

O trabalho da Comissão Nacional da Verdade tornou públicas as marcas da violência da ditadura militar sobre os povos tradicionais, apontando que o Estado brasileiro foi responsável pela morte de ao menos 8.350 indígenas.

\title{
3. As políticas para indígenas e práticas colonialistas: o direito à memória como serviço à justiça
}

Para manter o controle e o poder, a ditadura civil-militar brasileira fabricou uma memória governamental, por meio do uso da informação a partir de documentos oficiais. $\mathrm{O}$ regime militar foi estruturado e sustentado por um sistema de informações complexo, que controlava os distintos modos de produzir, processar, selecionar e divulgar as informações, e determinando os limites do que dizer e do quê registrar nos documentos (MORIGI, FORNO, 2020, p.2).

\footnotetext{
${ }^{5}$ Depois de 25 anos, acordo garante indenização de R $\$ 14$ milhões a Ashaninkas do AC por desmatamento. Disponível em: https://g1.globo.com/ac/acre/noticia/2020/04/02/depois-de-25-anos-acordo-garante-indenizacaode-r-14-milhoes-a-ashaninkas-do-ac-por-desmatamento.ghtml Acesso em: 30 mar. 2021.
} 
Nesse sentido, o trabalho da Comissão Nacional da Verdade teve importante papel desempenhado na construção do direito à memória enquanto resgate da identidade cultural do povo brasileiro, elemento defendido pela própria Constituição Federal de 1988:

Art. 216. Constituem patrimônio cultural brasileiro os bens de natureza material e imaterial, tomados individualmente ou em conjunto, portadores de referência à identidade, à ação, à memória dos diferentes grupos formadores da sociedade brasileira. $^{6}$

Em ensaio acerca da memória e políticas de esquecimento, Michel Pollak (1989, p. 03) destaca que embora a memória na maioria das vezes esteja ligada a fenômenos de dominação, o silêncio sobre o passado também está ligado nas relações entre grupos minoritários e sociedade englobante.

Nesse sentido, a inclusão dos povos indígenas como objeto de estudo na Comissão Nacional da Verdade revelou que os atingidos pela repressão não se limitavam apenas ao grupo de pessoas que se opunham ao regime. Além disso, as narrativas a respeito do período militar nunca tiveram o índio como foco, o que poderia dar a impressão de que a política repressiva passou longe das aldeias indígenas (VALENTE, 2017, p. 55).

Ao revelar informações obscuras desses povos, a CNV deu materialidade às narrativas, contribuindo para o resgate para o presente, da dor das vítimas, não como algo abstrato que está no passado, mas como sofrimento e injustiças que ainda persistem no presente.

Para a compreensão da constituição da memória indígena é necessária a reflexão acerca da construção da memória e identidade social. Michel Pollak (1989, p. 04) em reflexão teórica acerca do problema da identidade social em situações limites, discorre:

[...] a memória é um elemento constituinte do sentimento de identidade, tanto individual como coletiva, na medida em que ela é também um fator extremamente importante do sentimento de continuidade e de coerência de uma pessoa ou de um grupo em sua reconstrução de si.

O direito à memória vai em busca pela justiça e pela verdade. Na América Latina frente às graves violações de direitos humanos cometidas por suas ditaduras que terminou por desencadear o fenômeno da Justiça de Transição que, no dizer do secretário-geral da ONU, em2009, Kofi Annan (2009, p. 325) definiu como:

“[...] o conjunto de processos e mecanismos associados às tentativas da sociedade em chegar a um acordo quanto ao grande legado de abusos cometidos no passado, a fim

\footnotetext{
${ }^{6}$ BRASIL. Constituição (1988). Constituição da República Federativa do Brasil. Brasília, DF: Senado Federal: Centro Gráfico, 1988. Disponível em: http://www.planalto.gov.br/ccivil_03/constituicao/constituicao.htm. Acesso em: 10.01.2021. (caput do art. 216).
} 
de assegurar que os responsáveis prestem contas de seus atos, que seja feita a justiça e que se conquiste a reconciliação."

Dessa forma, a memória encontra-se no caminho entre a violência e a justiça. A função da memória é significar os atos de violência como algo inadmissível de ser normalizado pelo esquecimento. Assim, em síntese, pode-se concluir que a memória é um direito humano, porque sua ausência acarreta na repetição e na perpetuação de atos de violência e barbárie já vistos no passado, aumentando o número de vítimas.

De acordo com as pesquisadoras Fernanda Bragatto e Luciana de Paula enquanto as páginas cruéis da história brasileira não forem reveladas, nosso Estado, denominado "Democrático de Direito" no caput do art. $1^{\circ}$ da CF/88 anuirá, irracionalmente, a resquícios autoritários e policialescos e a com a aceitação, pela sociedade, de políticas violentas (BRAGATTO, PAULA, 2011, p. 139).

Considerando que os direitos fundamentais constantes da Constituição Federal representam um desfecho de todo um contexto histórico-cultural que foi inserto no ordenamento jurídico pátrio, é necessário retomar a Declaração Universal dos Direitos Humanos de 1948, como produto de uma racionalidade específica em que a ideia de dignidade humana foi construída tal como se concebe no mundo ocidental, adquirindo a hegemonia como linguagem da dignidade humana. De acordo com Zeifert e Agnoletto (2019, p. 205), grande parte da população mundial não é sujeito de direitos humanos, mas apenas objeto de seu discurso, pois possui outras linguagens de dignidade humana.

Boaventura de Sousa Santos (2013, p. 49) aponta que a hegemonia dos direitos humanos como linguagem representou, de certa maneira, um aniquilamento histórico dos grupos sociais oprimidos, considerando que existem outras linguagens de dignidade humana ao redor do mundo e outros sofrimentos além daqueles considerados violações dos direitos humanos:

[...] o discurso dominante dos direitos humanos passou a ser o da dignidade humana consonante com as políticas liberais, com o desenvolvimento capitalista e suas diferentes metamorfoses (liberal, socialdemocrático, dependente, fordista, pósfordista, fordista periférico, corporativo, estatal, neoliberal e etc.) e com o colonialismo igualmente metamorfoseado (neocolonialismo, colonialismo interno, racismo, trabalho análogo ao trabalho escravo, xenofobia, islamofobia, políticas migratórias repressivas e etc.). Temos, pois, de ter em mente que o mesmo discurso dos direitos humanos significou coisas muito diferentes em diferentes contextos históricos e tanto legitimou práticas revolucionárias como práticas contrarrevolucionárias. Hoje, nem podemos saber com certeza se os direitos humanos do presente são uma herança das revoluções modernas ou das ruínas dessas revoluções.

Assim, o resgate de episódios historiograficamente esquecidos, como é o caso do Massacre do Paralelo 11, restitui e reabilita a memória coletiva de povos tradicionais, 
possibilitando visibilidade e participação social de sua história e libertação para o futuro. No entanto, esse protagonismo somente poderá ser alcançado a partir de um giro decolonial incorporando saberes locais e avançando em processos de descolamento das bases eurocêntricas do conhecimento (COLAÇO, DAMÁZIO, 2012, p. 145).

\section{A possibilidade de olhar decolonial sobre os direitos fundamentais}

Entende-se por direitos fundamentais os direitos constitucionalmente assegurados com a finalidade de preservar a liberdade e a dignidade da pessoa humana. De acordo com Ingo Wolfgang Sarlet (2017, p. 3), os direitos fundamentais são:

\footnotetext{
"[...] conjunto de direitos e liberdades institucionalmente reconhecidos e garantidos pelo direito positivo de determinado Estado, tratando-se, portanto, de direitos delimitados espacial e temporalmente, cuja denominação se deve ao seu caráter básico e fundamentador do sistema jurídico do Estado de Direito."
}

Da perspectiva jurídico-formal a Constituição de 1988 inovou ao garantir aos povos tradicionais direitos organização social, costumes, línguas, crenças e tradições. No entanto, o silêncio histórico e a invisibilização dos povos indígenas acarretou num perfil normativo que excluiu as diferenças étnicas, inferiorizando e negando a cultura indígena o que levou a inefetividade das normas constitucionais. De acordo com Fernando Dantas (2014, p. 362), o processo de construção do Estado Nacional Brasileiro o direito positivo brasileiro revelou-se um moderno mecanismo de exclusão:

O longo processo de colonização e de construção do Estado Nacional brasileiro teve, no direito moderno positivado, um dos mais eficazes mecanismos de exclusão. Este, fundamentando a Política Indigenista do Estado, legitimou práticas genocidas, etnocidas e epistemicidas, responsáveis pela de população e pelo desaparecimento ou descaracterização de numerosas culturas e povos indígenas. Legitimou, também, a negação e a invisibilidade jurídica, social e cultural, ao normalizar conceitos depreciativos, como bárbaros e selvagens, ou generalizantes e reducionistas, como silvícolas e índios.

Ou seja: o colonialismo permaneceu impresso no ordenamento jurídico brasileiro nas tendências, mos estereótipos e nos pré-julgamentos excludentes da visão etnocêntrica europeia, conforme apontam Sparemberger e Kyrillos (2013, p. 03):

A colonização não diz respeito apenas à administração colonial direta sobre determinadas áreas do mundo, mas refere-se a uma lógica de dominação, exploração e controle que inclui a dimensão do conhecimento e também do conhecimento jurídico no Brasil. Nesse sentido, fala-se em colonialidade e não apenas de colonialismo.

Para se pensar numa perspectiva decolonial sobre os direitos fundamentais, faz-se necessário, como ponto de partida e bússola, considerar que o surgimento do pensamento 
decolonial emerge como movimento de oposição à modernidade sob a interpretação de que está encontra-se absorvida pela colonialidade. Trata-se, pois, de uma desobediência epistêmica como defende Walter Mignolo (2018, p. 05), e, por sua égide ter se dado justamente como movimento de resistência do pensamento indígena e afro-caribenho, assim como, com suas especificidades, em contextos asiáticos e africanos, num movimento de contraposição ao imperialismo britânico e ao colonialismo francês, é salutar que qualquer revolução do pensamento jurídico perpasse pelo processo de decolonização.

É nesse desiderato que a expressão "giro decolonial" cunhada pelo filósofo portoriquenho Nelson Maldonado (2007, p 07) caracteriza o movimento decolonial insurgido no final do Século XX e que carrega como significado "la apertura y la libertad del pensamiento y de formas de vida-otras (economías-otras, teorías políticas-otras); la limpieza de la colonialidad del ser y del saber; el desprendimiento de la retórica de la modernidad y de su imaginario imperial" (MIGNOLO, 2007, p. 08). O desafio se coloca como uma decolonização e uma descolonização, enquanto o decolonial como contraposição à "colonialidade", e o descolonial contraposição ao "colonialismo" (SANTOS, 2018, p. 15).

Nesse ínterim, pensar de forma decolonial e descolonial é refletir sobre a possibilidade de uma reconstrução epistemológica e hermenêutica que reconheça a pluralidade e a interculturalidade brasileiras, a nosso ver, com compromisso com a memória e a verdade ${ }^{7}$, notadamente para fins de reconfiguração dos direitos mais caros à humanidade, a saber aqueles que se encontram classificados como fundamentais.

Assim, no dizer de Roberto José Covaia Kosop e Edmilson de Souza Lima (2017, p. 2598) "pensar o campo jurídico a partir de saberes locais que rompam com as heranças coloniais, significa localizar os pontos iniciais do conhecimento latino-americano que abram espaços para questionamentos epistemológicos direcionados aos objetos particulares desta realidade".

A ideia de uma decolonização a partir do pano de fundo da luta pelo Direito de Memória tem o fim de demonstrar a importância da efetividade do direito à memória como forma de recuperar a identidade de um povo, comprometendo-se com o respeito aos direitos humanos e com o fortalecimento das instituições democráticas, sendo fundamental que nesse processo consigamos resgatar a história das políticas indigenistas a fim de contribuir para a reinstitucionalização da democracia no Estado brasileiro que depende, sobremaneira, da inclusão da multiculturalidade.

\footnotetext{
${ }^{7}$ Aqui utilizamos o termo "verdade" como referência ao resgate da memória indígena, especialmente no que tange à Comissão da Verdade, não inferindo, entretanto, que esta seja um conceito fechado.
} 
Nossa abordagem também caminha com a orientação dada pela Diretriz 23 do Programa Nacional de Direitos Humanos PNDH 3, a partir do eixo orientador VI - Direito á memória e verdade $^{8}$ que se dedica a resgatar a memória do período autoritário que se sucedeu ao Brasil Ditadura, considerando, entretanto, que ao longo da constituição do viver indígena na história dos direitos sociopolíticos no Brasil, o apagamento das narrativas indigenistas foram uma gravíssima lesão ao direito de existir. $\mathrm{O}$ objetivo é problematizar o direito à memória resgatando as lembranças dos ataques ditatoriais aos povos tradicionais brasileiros, em suas constituições identitárias e em suas lutas por reconhecimento, identificando os imbricamentos presentes entre o apagamento das narrativas sociopolíticas dos povos indígenas e o processo de redemocratização do Estado brasileiro.

De fato, o Direito como é ainda hoje no Brasil atual encontra-se arraigado pela violência da colonização e as premissas eurocêntricas que constituíram na história do pensamento jurídico brasileiro que teve desde sua gênese a finalidade precípua de manutenção das relações de exploração estabelecidas, por meio da transposição autoritária dos dogmas da Teoria Geral do Direito ocidental, especialmente no que tange ao monopólio do Estado na produção e validação das normas jurídicas e à individualização dos conflitos (WOLKMER, 1999, p. 33), o que pende sobremaneira na intersecção possível entre a consolidação das necessidades de instituição do debate acerca do diálogo decolonial com o pensamento jurídico contemporâneo.

No âmbito político, há uma tendência mundial, encabeçada pela extrema direita, de recrudescimento do conservadorismo vinculado ao neoliberalismo (SILVA, MACIEL, 2020, p. 02) que, contrariamente à luta pela exacerbação dos movimentos sociais, vem na contramão dessa premissa, instituindo discursos de ódio e alimentando o já existente apagamento das narrativas inclusivas (MARTINS, 2018, p. 03).

Observa-se cada vez mais o fortalecimento de ações e movimentos de caráter conservador e reacionário em diferentes campos, e particularmente no campo da educação, que se transforma em fértil terreno de disputa por esses segmentos. Neste contexto, torna-se ainda mais necessário ampliar nossa capacidade de compreensão desses movimentos, analisando suas fontes ideológicas, organizacionais e financeiras, além da participação ativa na construção de respostas para os crescentes desafios apresentados.

\footnotetext{
${ }^{8}$ BRASIL. Banco de Dados Direitos Humanos DHnet. Programa Nacional de Direitos Humanos PNDH 3. Secretaria Especial dos Direitos Humanos da Presidência da República. Disponível em http://www.dhnet.org.br/pndh/6memoria/index.htm. Acessado em 05.10.2020
} 
No contexto brasileiro, estamos vivendo uma tentativa de apagamento da memória da resistência política ${ }^{9}$, com especial ênfase ao período do regime ditatorial instaurado em 64 e atualmente ovacionado pelo Governo Federal $^{10}$ :

Sob a frágil democracia brasileira, sofre agora uma tentativa de revesti-la de uma qualidade "revolucionária" quando, na verdade, representa um crime humanitário ainda impune no Brasil. Parte desta estratégia é o apagamento da memória social, da militância, dos sujeitos políticos que contestaram o regime ditatorial, instaurado em $64^{11}$.

Acreditamos que o exercício de demonstrar os impactos da repressão do Regime Militar à população indígena, possa ser um parâmetro para dialogar acerca da efetividade dos direitos fundamentais constitucionalmente consagrados através de um processo de resgate de memória que aqui enfatizamos a partir da recontagem e do resgate do nominado Massacre do Paralelo 11 - ocorrido no norte do Estado de Mato Grosso, contra o povo cinta-larga, enquanto forma de trazer a necessidade de se discutir o princípio da dignidade da pessoa humana fundamentado no direito à memória indígena e na decolonização do pensamento jurídico.

Isso porque, no âmbito do campo jurídico, não se pode olvidar que o direito não pode se manifestar tão somente no âmbito normativo, e, especialmente haja vista sua fundação gnosiológica altamente hegemônica e excludente, merecendo a inclusão dos sujeitos quais foram ao longo da história do pensamento jurídico brasileiro, altamente negligenciados, como é o exemplo possível de se fazer a partir da necessidade do resgate da verdade indígena. A nós trata-se de uma luta pelo direito à memória, mas também uma reconstrução identitária que se legitima também como estratégia sociopolítica e jurídica de resistir.

\section{Considerações Finais}

A abordagem por meio do método materialista histórico dialético de Evgeni Pachukanis, sob uma perspectiva jusfilosófica, procurou demonstrar o impacto da repressão do Regime Militar à população indígena, diante do recorte de lócus Mato Grosso e em face do povo Cinta-

\footnotetext{
${ }^{9}$ Pelo direito à memória como ato da luta política feminista. SOS CORPO - Instituto Feminista para a Democracia. Dossiê Memórias: Trajetória de Resistências Arquivo SOS Corpo. Disponível em https://soscorpo.org/?p=7691. Acesso em 04 fev. 2021.

10 Notícia amplamente difundida nacional e internacionalmente: Disponível em GI GLOBO https://g1.globo.com/politica/noticia/2019/03/27/bolsonaro-comemora-ditadura-brutal-diz-human-rights-watchsobre-determinacao-para-aniversario-do-golpe-de-64.ghtml; BBC https://www.bbc.com/portuguese/brasil47741593; ; IMPRENSA INTERNACIONAL https://g1.globo.com/mundo/noticia/2020/04/19/imprensainternacional-repercute-participacao-de-bolsonaro-em-ato-que-pedia-intervencao-militar.ghtml

11 Pelo direito à memória como ato da luta política feminista. SOS CORPO - Instituto, Feminista para a Democracia. Dossiê Memórias: Trajetória de Resistências Arquivo SOS Corpo. Disponível em https://soscorpo.org/?p=7691. Acesso em 04 fev. 2021.
} 
Larga a partir do nominado Massacre do Paralelo 11, mas representa somente uma das faces das atrocidades cometidas diante da reificação dos povos tradicionais desde o Brasil colônia e que perdura ao longo dos séculos.

Procuramos dialogar acerca da efetividade dos direitos fundamentais constitucionalmente consagrados, mediante o princípio da dignidade da pessoa humana fundamentado no direito à memória indígena e na decolonização do pensamento jurídico. Partimos do pressuposto de que tanto a historiografia quanto o direito nacional destinaram um local secundário aos povos tradicionais brasileiros e por isso a Comissão Nacional da Verdade desempenha um importante papel no resgate da dignidade dos povos tradicionais à partir de seu direito de memória.

Operamos nossa análise mediante o método dedutivo e a partir da metodologia de revisão bibliográfica e documental com o resgate das fotografias de material jornalístico e documentos presentes no Relatório Figueiredo, o objetivo principal é o de dialogar a partir da experiência do real, em face da norma jurídica e a necessidade de rever a reificação dos povos indígenas no Estado Democrático de Direito.

Entendemos que a relação entre direito fundamental e memória é ponto crucial para a decolonização do pensamento jurídico e se faz como elemento primordial para a revanche jusfilosófica da história nacional, especialmente porque em face da memória como constituição de identidade e a luta pelo reconhecimento são parte indiscutível pelo movimento de exercer efetivamente os direitos fundamentais dos povos tradicionais e colaborar dessa forma pra uma reconfiguração de nossa identidade brasileira com maior eficácia constitucional.

\section{Referências}

ANNAN, Kofi. O Estado de Direito e a justiça de transição em sociedades em conflito ou pós-conflito. Relatório S/2004/616 apresentado ao Conselho de Segurança da ONU em 23.08.04. Revista Anistia Política e Justiça de Transição, $n^{o} .01$ pp. 320-351, Brasília, jan/jun, 2009.

BARBOSA, Rodrigo Lins. O Estado e a Questão Indígena: Crimes e corrupção no SPI e na FUNAI (1964-1969). 2016. 260 p. Dissertação (Mestrado em História) Universidade Federal de Pernambuco, Recife, 2016.

BRAGATTO, Fernanda; PAULA, Luciana Araujo de. A memória como direito humano. In: Assembléia Legislativa do Estado do Rio Grande do Sul. Comissão de Cidadania e Direitos Humanos. Relatório Azul 2011. p. 129-141. Porto Alegre: ALERS, 2011.

COLAÇO, Thais Luzia. DAMAZIO, Eloise da Silveira Petter. Novas perspectivas para a antropologia jurídica na América Latina: o direito e o pensamento decolonial - Volume IV. Florianópolis: Editora UFSC, 2012. 
CRUZ, Soraya Sarría. La Contratación Económica En El Ministerio del Azúcar Durante los Últimos Cinco Años. 2011. 180 p. Tesis en opción al grado de Máster en Derecho Agrario. Universidad de la Habana, La Habana, 2011.

DANTAS, Fernando Antonio de Carvlho Descolonialidade e direitos humanos dos povos indígenas. Revista de Educação Pública. [S. 1.], v. 23, n. 53/1, p. 343-367, 2014. Disponível em: https://periodicoscientificos.ufmt.br/ojs/index.php/educacaopublica/article/view/1621. Acesso em: 25 mar. 2021.

HENNING, Ana Clara Correa. BARBI, Milena. APOLINÁRIO, Marcelo Nunes. Para uma compreensão de decolonização jurídica latinoamericana, Revista CCCSS Contribuciones a las Ciencias Sociales. [S. 1.], (enero-marzo 2016). Disponível em:

http://www.eumed.net/rev/cccss/2016/01/decolonizazao.html, Acesso em: 03 fev. 2021.

KOSOP, Roberto José Covaia; LIMA, José Edmilson de Souza. Giro Decolonial e o Direito: Para Além de Amarras Coloniais. Rio de Janeiro: Rev. Direito Práx. v. 10, n.4, 2019, p. 25962619. Disponível em: https://www.scielo.br/j/rdp/a/XK3xFx3R8yWRpPFCrSyxD8t/?lang=pt. Acesso em: 23 mar. 2021.

LIMA, Edilene Coffaci de. Entrevista com Marcelo Zelic. Sobre o Relatório Figueiredo, os indígenas na Comissão Nacional da Verdade e a Defesa dos Direitos Humanos. Mediações Revista de Ciência Sociais, v. 22, n. 2, 2017, p. 347-365. Disponível em: http://www.uel.br/revistas/uel/index.php/mediacoes/article/view/32262/pdf. Acesso em: 02 fev. 2021.

MIGNOLO, W. D. El pensamiento decolonial: desprendimiento y apertura. Un manifiesto. In S. C. Gómez \& R. Grosfoguel (Org), El giro decolonial: reflexiones para una diversidad epistémica más allá del capitalismo global. Bogotá: Instituto Pensar, 2007, p 25-46.

Disponível em: http://www.ceapedi.com.ar/imagenes/biblioteca/libreria/147.pdf. Acesso em: 21 mar. 2021.

MIGNOLO, W. D. Desobediência epistêmica: a opção descolonial e o significado de identidade em política. Cadernos de Letras da UFF - Dossiê: Literatura, língua e identidade, [S. 1.], no 34, 287-324, 2008. Disponível em:

http://professor.ufop.br/sites/default/files/tatiana/files/desobediencia_epistemica_mignolo.pdf. Acesso em: 28 mar. 2021.

MARTINS, Marcos Francisco; GROPPO, Luis Antonio; BARBOSA, Jefferson Rodrigues. Apresentação do dossiê temático: movimentos sociais conservadores e educação. Crítica Educativa, Sorocaba, vol. 4, n. 2, p. 3-6, Set./ Out.2018. Disponível em: https://www.criticaeducativa.ufscar.br/index.php/criticaeducativa/article/view/366/392. Acesso em: 27 mar. 2021.

MORIGI, V. J.; FORNOS, A. M. G. Direito à memória: a comissão nacional da verdade brasileira e as narrativas dos povos indígenas na construção da cidadania. Informação \& Sociedade: Estudos, v. 30, n. 2, 2020. Disponível em: 10.22478/ufpb.18094783.2020v30n2.52156. Acesso em: 02 mar. 2021.

NADER, Paulo. Filosofia do Direito. São Paulo: Forense, 2010. p. 30-56. 
NETO, João Dal Poz. No país dos Cinta Larga: uma etnografia do ritual. 1991. 408 p. Tese (Doutorado em Antropologia Social) Universidade de São Paulo, São Paulo, 1991.

PACHUKANIS, Evgeni Bronislávovich. A Teoria Geral Do Direito E Marxismo. Traduzido e apresentado por notas por Paulo Bessa. - Rio de Janeiro: Renovar, 1989. p. 38 e 39.

POLLAK, Michael. Memórias, esquecimento, silêncio. Revista Estudos Históricos, Rio de Janeiro, v. 2, n. 3. p. 3-15, jun. 1989. Disponível em:

http://bibliotecadigital.fgv.br/ojs/index.php/reh/article/view/2278. Acesso em 02 fev. 2021.

RIBEIRO, Darcy. Os índios e a civilização - A integração das populações indígenas ao Brasil Moderno. São Paulo: Companhia das Letras, 1996.

SANTOS, Boaventura de Sousa. CHAUÍ, Marilena. Direitos humanos, democracia e desenvolvimento. São Paulo: Cortez, 2013.

SANTOS, Vívian Matias dos. Notas desobedientes: decolonialidade e a contribuição para a crítica feminista à ciência. Psicol. Soc. 30. Belo Horizonte: dez.2018. Disponível em: http://www.scielo.br/scielo.php?script=sci_arttext\&pid=S0102-

71822018000100242\&lng=en\&nrm=iso. Accesso em: 03 mar. 2021.

SARLET, Ingo Wolfgang. Conceito de direitos e garantias fundamentais. Enciclopédia jurídica da PUC-SP. Ceolso Fernandes Campilongo, Alvaro de Azevedo Gonzaga e André Luiz Freire (coords.). Tomo: Direito Administrativo e Constitucional. Vidal Serrano Nunes Jr., Maurício Zockun, Carolina Zancaner Zockun, André Luiz Freire (coord. de tomo). 1. ed. São Paulo: Pontifícia Universidade Católica de São Paulo, 2017. Disponível em:

https://enciclopediajuridica.pucsp.br/verbete/67/edicao-1/conceito-de-direitos-e-garantiasfundamentais Acesso em: 24 mar. 2021.

SILVA, Segislane Moésia Pereira da; MACIEL, Valnise Verás; FRANCA, Marlene Helena de Oliveira. Conservadorismo como instrumento capitalista em tempos de barbárie. Revista Katálysis, Florianópolis, v. 23, n. 2, p. 256-265, ago. 2020. Disponível em http://www.scielo.br/scielo.php?script=sci_arttext\&pid=S1414$49802020000200256 \& \operatorname{lng}=$ pt\&nrm=iso. Acesso em 06 fev 2021.

SPAREMBERGER, Raquel Fabiana Lopes; KYRILLOS, Gabriela de Moraes. Desafios coloniais e interculturais: o conhecimento jurídico colonial e o subalterno silenciado. Revista Contribuciones a Las ciencias sociales. Universidad de Málaga, Espanha, 2013. Disponível em: http://www.eumed.net/rev/cccss/24/colonialidade.html. Acesso em 22 mar. 2021.

Survival Brasil. Disponível em: https://www.survivalbrasil.org/ultimas-noticias/9197. Acesso em 30 mar. 2021.

VALENTE, Rubens. Os fuzis e as flechas: História de sangue e resistência indígena na ditadura. São Paulo: Companhia das Letras, 2017. p. 07-220.

WOLKMER, Antônio Carlos (Org.). História do Direito no Brasil. Rio de Janeiro: Forense, 1999. p. 24-39. 
ZAGO, Luis Henrique. O método dialético e a análise do real. Kriterion [online]. [S. 1.], 2013, vol.54, n.127, pp.109-124. Disponível em:

scielo.br/j/kr/a/tMzcgmXNY3NJS3MY3MZBSxH/?lang=pt. Acesso em: 20 fev. 2021.

ZEIFERT, Ana Paula Bagetti. AGNOLETTO, Vitória. O pensamento descolonial e a teoria crítica dos direitos humanos: saberes e dignidade nas sociedades latinoamericanas. Revista Humus. v. 9, n. 26, p. 197-217, São Luís, 2019. Disponível em:

http://www.periodicoseletronicos.ufma.br/index.php/revistahumus/article/view/12077. Acesso em: 27 fev. 2021.

\title{
El massacre del paralelo 11 y los derechos fundamentales a partir del derecho a la memória indígena y la decolonización del derecho brasileño
}

\begin{abstract}
Resúmen
Este artículo tiene como objetivo mostrar el impacto de la represión del Régimen Militar a la población indígena, a partir denominado Masacre del Paralelo 11, que se ocurrió en el norte del estado de Mato Grosso, contra el pueblo Cinta-Larga, como parámetro para dialogar sobre la efectividad de los derechos fundamentales constitucionalmente consagrados, mediante el principio de la dignidad de la persona humana, fundamentado em el derecho a la memoria indígena y em la decolonización del pensamiento jurídico. Se adoptó el método dialéctico materialista histórico de Evgeni Pachukanis para dialogar desde la experiencia de la realidad, la relación entre la norma jurídica y la necesidad de revisar la cosificación de los pueblos indígenas en el Estado Democrático de Derecho. Así, investigamos los trabajos de la Comisión Nacional de la Verdad y luego conceptualizamos la memoria y los derechos fundamentales, para analizar cómo la memoria en sus constituciones identitarias y luchas por el reconocimiento y descolonización del pensamiento jurídico nacional son necesarias para el ejercicio de los derechos fundamentales por parte de los pueblos tradicionales.
\end{abstract}


Palabras-clave: Indígenas; Derechos fundamentales; Decolonización; Memoria; Dignidad de la persona humana.

\title{
Le massacre du parallèle 11 et des droits fondamentaux fondés sur le droit à la mémoire indigène et la décolonisation du droit brésilien
}

\begin{abstract}
Résumé
Cet article vise à démontrer l'impact de la repression du régime militaire sur la population inidigène, à partir du massacre du parallèle 11, qui s'est passé dans le nord de l'État du Mato Grosso, contre le peuple Cinta-Larga, comme parameter de dialogue sur l'efficacité des droits fondamentaux consacrés par la Constitution, moyennant le principe de la dignité de la personne humaine fondée sur le droit à la mémoire indigène et la décolonisation de la pensée juridique. Pour cette étude, nous avons adopté la méthode matérialiste historico-dialectique d'Evgeni Pachukanis pour dialoguer à partir de l'expérience du réel, le rapport entre la norme juridique et la nécessité de revoir la réification des peuples indigènes dans l'État démocratique de droit. Ainsi, nous enquêtons sur les travaux de la Commission nationale de vérité et nous conceptualisons la mémoire et les droits fondamentaux, pour enfin analyser comment la mémoire dans ses constitutions identitaires et dans ses luttes pour la reconnaissance et la décolonisation de la pensée juridique nationale sont nécessaires à l'exercice des droits fondamentaux par les peuples traditionnels.
\end{abstract}

Mots-clés: Indigène; Droits fondamentaux; Décolonisation; La mémoire; Dignité de la personne humaine.

\section{The parallel 11 massacre and the fundamental rights from indigenuos memory right and the decolonization of brazilian law}

\begin{abstract}
This article aims to demonstrate the impact of Brazilian military dictatorship against the indigenous population, from the so-called Parallel 11 Massacre, which took place in Northern Mato Grosso state, against the Cinta-Larga indigenous people, as a parameter to dialogue about how effective fundamental rights are, constitutionally granted, through the principle of dignity of the human being, which is founded on the law regarding indigenous memory and on decolonization of judicial thought. We have adopted for this paper Evgeni Pachukanis's materialist historical dialectic method to dialogue from the reality's perspective, the relationship among legal norm and the need to review and indigenous people's reification in a law democratic state. Thus, we have investigated the works from Brazilian Truth National Commission. Afterwards, we have conceptualized memory and fundamental rights, so that, in the end, we are able to analyse how memory on its identity constitutions and within its fights for recognition and decolonization of national legal thought are necessary for carrying out fundamental rights by traditional people.
\end{abstract}

Keywords: Indigenous people; Fundamental rights; Decolonization; Memory; Human being dignity. 